\title{
RELATIVIZACIÓN DE LA IMPORTANCIA DE LA PARTITURA EN LA EDUCACIÓN MUSICAL: UNAS CONSECUENCIAS PEDAGÓGICAS
}

Artículo de reflexión

DOI 10.14483/udistrital.jour.c14.2016.2.a12

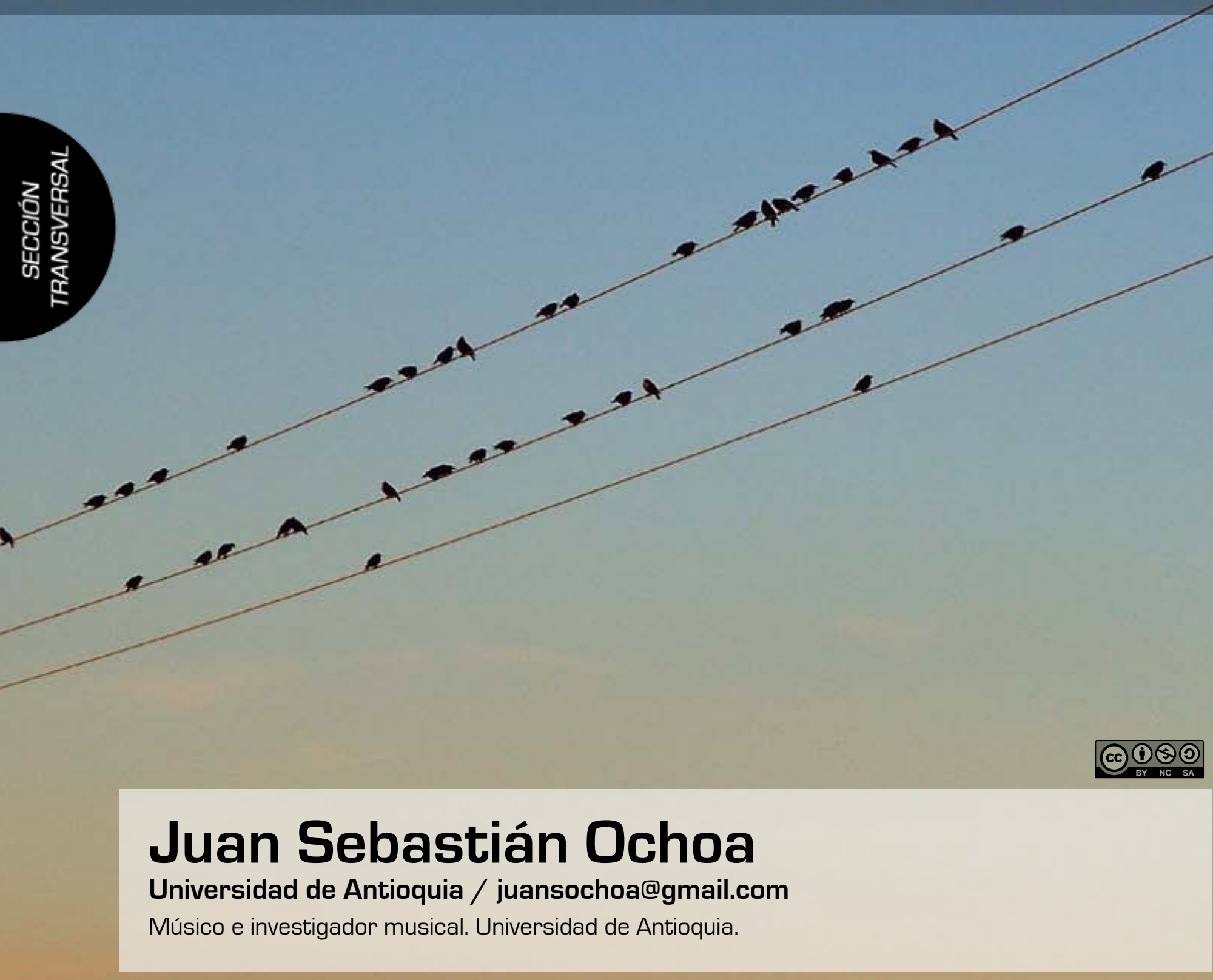


Ochoa J. Relativización de la importancia de la partitura en la educación musical: Unas consecuencias pedagógicas. Calle 14, 11 [19] pp 140-151

\title{
RELATIVIZACIÓN DE LA IMPORTANCIA DE LA PARTITURA EN LA EDUCACIÓN MUSICAL: UNAS CONSECUENCIAS PEDAGÓGICAS
}

\begin{abstract}
RESUMEN
El texto plantea una mirada crítica al papel actual de la partitura convencional occidental dentro de la educación musical formal y, propone, a partir de una reflexión sobre el carácter ontológico de la partitura como herramienta de uso descriptivo y prescriptivo [siguiendo la propuesta del musicólogo Charles Seeger], tres consecuencias pedagógicas que se desprenden de relativizar la importancia de la partitura en los tiempos actuales: ampliar la noción de notación musical, privilegiar una educación musical sonoro-corporal, y hacer un uso mayor de las nuevas tecnologías de grabación y reproducción en el aula. La conclusión es que una relativización de la partitura debe llevarnos a una educación musical necesariamente menos racionalizada y más sonoro-corporal, menos leída y más vivida.
\end{abstract}

PALABRAS CLAVE

Música, educación musical, partituras, pedagogía.

\section{RELATIVIZACIÓN AJAI MINISTIDU IACHACHINGAPA TUNAPI TUKUIKUNATA KAWAN- CHINGAPA}

\section{MAILLALLACHISKA}

Ninakumi imasami kawankuna mana allilla kai kilkaita,tukuikuna iachachispa allilla kaachispa parlaspa kusaikuna suti intilógia sug rurai ministdu sug runa suti Charles Seeger, rimariska pai iachachi kallarigapa tukui munaskakunata tunai rurangapa Maskaspa iachachingapa kunauramanda kunata, kachu mas kilkaska kausaskata parlachukuna Chasa allilla kawaringami.

\section{RIMANGAPA MINISTISKAKUNA}

Tunai tunangapa ichachii, ruraikuna pintai allilla kawaspa iachaikui.

\section{RELATED TO SCORE SIGNIFICANCE IN MUSICAL EDUCATION: SOME PEDAGOGICAL CONSEQUENCES}

\begin{abstract}
This written piece of work proposes a critic look at the actual role the occidental conventional score has in the formal education level. Moreover, following Charles Seeger's musicologist proposal, this text also intends to show a reflection on the ontological character of scores as a tool of descriptive and prescriptive use, resulting three pedagogical consequences appearing from making the score importance relative at present. In other words, widening the musical notation notion, giving privilege to a resonant-corporal musical education, and insisting on a better use of technologies in recording and reproduction techniques in the classroom. As a final point, it is important to highlight that making the score importance relative can lead us to a resonant-corporal education instead of to a rationalized one which consequently may not be widely read but lived.
\end{abstract}

\section{KEYWORDS}

Music, musical education, scores, pedagogy. 


\section{RELATIVITÉ DE L'IMPORTANCE DE LA PARTITION DANS L'ÉDUCATION MUSICALE. LES CONSÉQUENCES PÉDAGOGIQUES}

\section{RÉSUMÉ}

Le texte propose un regard critique au rôle actuel de la partition conventionnelle d'occident dans l'éducation musicale formelle. Formule á partir de la réflexion sur le caractère ontologique de la partition comme un outil d'usage descriptif et prescriptif [en suivant la proposition du musicologue Charles SEEGER] Trois conséquences pédagogiques qui se détachent de relativiser l'importance de la partition actuellement : 1] Élargir la connaissance de notation musicale, 2] Privilégier une éducation musicale sonore-corporelle et 3) Faire une utilisation plus vaste des technologies d'enregistrement dans la salle de classe. En conclusion, une relativisation de la partition doit nous verser à une éducation musicale moins rationalisée et plus sonore-corporelle, moins lue et plus vécue.

\section{MOTS CLÉS}

Musique, éducation en musique, partition, pédagogie.

\section{RELATIVIZAC̄̃̃O DA IMPORTÂNCIA DA PARTITURA NA EDUCAC̄̃̃O MUSICAL: UMAS CONSEQUÊNCIAS PEDAGÓGICAS}

\section{RESUMO}

O texto propõe uma olhada crítica ao papel atual da partitura convencional ocidental dentro da educação musical formal e, propõe, a partir de uma reflexão sobre o caráter ontológico da partitura como ferramenta de uso descritivo e prescritivo [sendo a proposta do musicólogo Charles Seeger], três consequências pedagógicas que se desprendam De relativizar a importância da partitura nos tempos atuais: ampliar a noção de notação musical, privilegiar uma educação musical sonoro-corporal, e fazer um uso maior das novas tecnologias de gravação e reprodução na aula. A conclusão é que uma relativização da partitura deve levános a uma educação musical necessariamente menos racionalizada e mais sonoro-corporal, menos lida e mais vivida.

\section{PALAVRAS-CHAVE}

Música, educação musical, partituras, pedagogia. 


\section{Introducción}

En la educación musical formal, ya sea en academias, conservatorios o universidades, la partitura ha ocupado un lugar primordial [O'Brien, 2010; Green, 2001; Ochoa, 2011; Hopkins, 1966]. Como parte de la cultura hegemónica de Occidente, la educación musical ha privilegiado la tradición escrita sobre la oral, lo racional sobre lo emotivo y sensorial, la mente sobre el cuerpo. A tal punto ha llegado la valoración de la partitura en el campo musical que es frecuente encontrar una asociación entre la capacidad de lecto-escritura musical con el hecho de ser un "verdadero" músico, o un músico "profesional", de tal manera que los músicos formados por tradición oral serían simples aficionados o sencillamente no serían músicos ${ }^{1}$. Para el tema que me interesa en este texto, quiero enfatizar en que esta valoración de la partitura en la educación musical formal ha llevado a pensarla como la música misma, ha llevado a confundir la partitura con la música. Desde este punto de vista, el compositor es aquella persona que crea partituras, y analizar música equivale a analizar partituras.

Esta forma de comprender la partitura, si bien de uso común en diferentes ámbitos [no solo en el de la educación formal), parte del error de confundir la representación con el objeto representado. Como expliqué en detalle en otro texto, la partitura es en esencia una representación de un hecho sonoro y, como toda representación, no es igual al objeto representado y ontológicamente no puede tomar su lugar?.

El que la educación musical universitaria hegemónica mantenga esa confusión de valorar la partitura como la música, privilegiando lo visual sobre lo sonoro, tiene efectos concretos en las prácticas pedagógicas en el interior del aula: el uso que se le da a la partitura entendida de esta forma lleva a emplearla en casos en los que quizás no es lo más útil, y a su vez lleva a ignorar herramientas y prácticas pedagógicas diferentes que en ocasiones pueden ser más relevantes y pueden aportar nuevas formas de enseñanza-aprendizaje.

1. Esto ha hecho que en ocasiones se piense que el músico profesional es aquel que "sabe leer y escribir partituras, aquel músico alfabetizado que domina el lenguaje escrito, y deja de un lado el pensar si ese músico puede o no hacer música, producirla, interpretarla" [Ochoa, 2011, pp. 60-61).

2. A este fenómeno, Edward Said lo llama con el nombre de "textualismo". Para Said, con el textualismo "la idea que subyace es que los hombres, los lugares y las experiencias se pueden describir siempre en un libro, de tal modo que el libro [o el texto] adquiere una autoridad y un uso mayor incluso que la realidad que describe" [2004, p. 136]. Esto es justo lo que con frecuencia ocurre en la educación musical: las partituras adquieren una autoridad y un uso mayor que la música que describen. El textualismo en parte se debe a que el proyecto moderno civilizatorio ve a la tradición oral como símbolo de atraso y a la tradición escrita como manifestación del progreso, señal de modernidad [Muñoz, 2009].
Para presentar esta discusión organizo el texto de la siguiente manera: primero haré una reflexión sobre el sentido ontológico de la partitura, con el fin de ubicar el problema en términos conceptuales y teóricos. Luego, presentaré tres consecuencias macro que se pueden derivar de esa conceptualización para la pedagogía musical. Por último, daré unas breves conclusiones.

\section{Acerca del sentido de la partitura convencional occidental}

Usualmente, cuando pensamos en notación o transcripción musical pensamos en partituras convencionales de la escritura musical en Occidente. Pensamos en pentagramas con notas [blancas, negras, ...), silencios, barras de compás, claves, armaduras, entre otras. En este punto vale la pena preguntarnos por el estatuto ontológico de una partitura de este tipo. Dicho en términos más simples, ¿qué es una partitura?

Habiendo dicho ya que una partitura no es la música sino una representación, podemos señalar que las partituras convencionales representan principalmente las alturas y el ritmo de una música, y pueden dar algunas indicaciones sobre las dinámicas, la articulación, el timbre y los cambios de tempo. Sin embargo, en estos últimos parámetros la representación resulta muy somera, mucho más imprecisa de lo que puede serlo para las alturas y el ritmo. La partitura es, entonces, una forma particular de notación musical gráfica, entendiendo por notación musical toda "analogía visual de un sonido musical" (Bent, et al., 2014) ${ }^{3}$.

En su ya clásico artículo acerca de la notación musical, el musicólogo Charles Seeger ofrece una tipología a partir de dos grandes grupos: la notación prescriptiva y la descriptiva [Seeger, 1958]. La notación prescriptiva es aquella que tiene como objeto determinar cómo debe sonar una pieza musical. Se trata de una notación subjetiva en cuanto depende de lo que el compositor quiera colocar en ella. La notación descriptiva es aquella que sirve como reporte de cómo sonó una interpretación particular. Según Seeger, se trata de una notación objetiva en cuanto busca describir un hecho ya sucedido, busca representar objetivamente una música ya interpretada.

Al pensar la notación convencional occidental en estos términos, Seeger dice:

Su carácter es casi en su totalidad prescriptivo, y el énfasis está en las estructuras - principalmente la altura y el metro-. No nos dice mucho acerca de las conexiones entre las estructuras. No nos dice tanto acerca de cómo la música suena sino de cómo debería hacerse sonar. Pero

3. Para un recuento de las principales aproximaciones que los estudiosos de la música han hecho con respecto a las transcripciones, ver Ellingson [1979). 


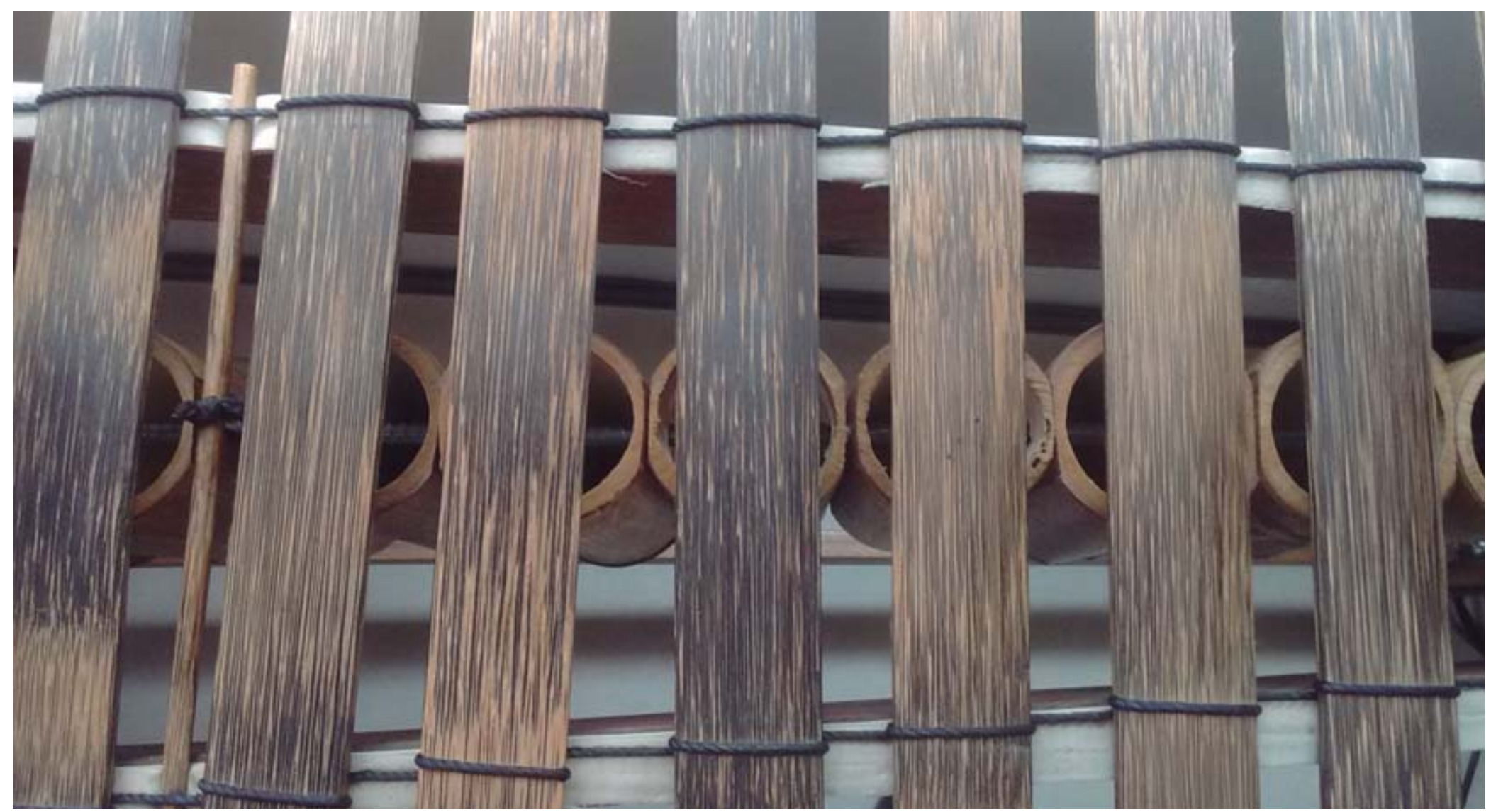

- Marimba de chonta. Fotografía: Juan Sebastián Ochoa, 2015.

nadie podría hacerla sonar como pretendió quien la escribió originalmente, a menos que posea el conocimiento de la tradición de la escritura y también el conocimiento oral [o mejor, aural] de la tradición asociada a ella. En otras palabras, que posea la tradición musical que aprende el estudiante por oído, en parte gracias a sus familiares y sus amigos, pero especialmente gracias a los preceptos de sus maestros. Es en esta tradición aural donde generalmente queda el conocimiento de "lo que pasa entre las notas" [1958, p. 186).

En esta cita se encuentran dos de los aportes más significativos del texto de Seeger: ${ }^{1}$ J lo que está "entre las notas" no lo puede representar la notación convencional, lo cual hace evidente el carácter parcial de dicha notación, y ${ }^{2}$ ] no es posible reproducir una partitura sin estar familiarizado con el lenguaje musical [en términos de género y estilo] en el que se encuadra la obra escrita.

El primer punto hace explícito que la notación musical convencional se basa principalmente en colocar puntos de una cadena, donde cada punto representa una altura y un momento en el tiempo [frecuencia y ritmo], de tal manera que la música queda representada como secuencias de puntos que deben conectarse entre sí. Cómo se pasa de un punto de la cadena a otro es algo que la notación no nos dice (o nos lo dice muy vagamente a partir de otros recursos como las ligaduras, stacatto, entre otros]. Y aquí es donde el segundo punto de Seeger se torna relevante: la manera correcta de unir los puntos nos muestra la tradición musical a la cual está asociada esa partitura. Esto indica que la tradición oral es el soporte de toda tradición musical o, como dice Hopkins: "no hay tal cosa como una tradición no oral en música” [1966, p. 311]4.

Además de la dificultad de la partitura convencional para describir qué pasa "entre las notas" [between the notes en términos de Seeger], con la aparición de los instrumentos eléctricos y electrónicos [sintetizadores, guitarras eléctricas, entre otros] se hizo evidente otra limitación de este tipo de notación: el timbre. El compositor Brian Eno fue quizás uno de los primeros en señalar esta dificultad. Sin poseer formación académica musical, y dedicado a componer a partir de sintetizadores y equipos eléctricos y electrónicos, Eno produce su música directamente sobre la grabadora. Al preguntársele en una entrevista acerca de por qué nunca aprendió a leer partitura dijo:

No habría sido muy útil. Ha habido una o dos ocasiones donde yo estaba en alguna parte sin mi grabadora de cinta y tenía una idea, trataba de memorizarla, y como una buena idea casi siempre recae en un detalle

4. Sin embargo, algunos compositores contemporáneos reivindicarían la idea de tener tradiciones musicales exclusivamente escritas, e incluso han propuesto realizar partituras que no deban ser o no requieran ser interpretadas, sino que sean valiosas en sí mismas, valorándose principalmente en su contenido gráfico. Este es el caso, por ejemplo, de la obra Treatise, de Cornelius Candrew, en la cual la notación misma puede ser considerada una forma de arte. El mismo autor decía con respecto a su obra: "La notación es más importante que el sonido. No la exactitud y el éxito con el que la notación represente el sonido, sino la musicalidad de la notación en sí misma" (Stamp, 2012). Siendo estos casos una excepción, no los considero relevantes para el argumento de este texto. 
poco familiar, es entonces automáticamente difícil de recordar. Entonces, en esas muy inusuales ocasiones he pensado 'Dios, si tan solo yo pudiera escribir esto'. Pero de hecho, la mayoría de lo que yo hago tiene que ver con texturas sonoras, y usted no puede notar eso de ninguna manera. Eso se debe a que la notación musical surgió en un momento en que las texturas sonoras eran limitadas. Si usted decía violines y maderas eso definía la textura sonora, pero si yo digo sintetizador y guitarra eso no significa nada, usted está hablando de 28000 posibilidades [Stamp, 2012].

Las variaciones del timbre de un instrumento, o de la textura sonora de una grabación, es algo para lo cual las partituras convencionales no son útiles, algo para lo cual no fueron pensadas, siendo esta una limitación más en su capacidad representativa.

En el momento en que Seeger publicó este artículo, su búsqueda y la de otros musicólogos estaba centrada en encontrar el modo de representar gráficamente más y más parámetros de la música, y con mayor precisión, de tal manera que pudiera realizarse una objetivación de los hechos sonoros de una forma "científica" que permitiera comparar diferentes músicas con un nivel de rigor y neutralidad valorativa que hicieran de la musicología una ciencia según los criterios positivistas de la época. Sin embargo, una de las dificultades que rápidamente encontraron era que mientras más complejas y detalladas se hacian las notaciones, menos legibles e interpretables lograban ser. El nivel de detalle y la capacidad de interpretación de los datos parecían ir en relación inversa. Si bien las partituras convencionales resultan relativamente fáciles de leer para un músico educado en la tradición, su capacidad de representación está principalmente en las alturas y las duraciones de las notas. A medida que se agregan símbolos a las partituras para tratar de representar otros parámetros musicales, estas se vuelven más y más difíciles de leer.

En este intento, Seeger desarrolló un equipo eléctrico que permitía realizar gráficos a partir de grabaciones hechas en cinta magnética. A esta máquina la llamó el melógrafo. Con este equipo pensaron que podrían llegar a lograr unas representaciones gráficas muy precisas de diferentes parámetros musicales de una grabación, pero al poco tiempo descubrieron que la dificultad de lectura e interpretación de los datos era tal que la empresa resultaba improductiva, por lo cual no insistieron en esa línea.

En este punto resulta relevante recordar la célebre metáfora de Jorge Luis Borges en su cuento "Del rigor en la ciencia” [1998 [1960], p. 40], en el cual plantea la creación de un mapa en escala 1:1 de un imperio. Dicho mapa, por ser exactamente igual al objeto que representa [ser un imperio que representa un imperio] resulta inútil para comprender ese imperio. Así, Borges nos recuerda que toda representación, si busca utilidad, implica una tarea de reducción, de selección de los parámetros a representar, de ordenamiento y clasificación. Toda representación es entonces un proceso subjetivo que implica una mirada analítica y crítica, y por lo tanto parcial, de lo que se requiere representar. Una partitura es entonces una especie de mapa útil de lo musical, una aproximación gráfica -entre muchas posibles, con sus ventajas y desventajas- a un hecho sonoro ${ }^{5}$.

Pero, ¿qué utilidades tiene la partitura? Volviendo con la idea de Seeger, la notación musical puede ser prescriptiva cuando indica cómo debe ser interpretada una obra, y descriptiva cuando indica cómo fue cierta interpretación particular de una obra. No obstante, puede ser más importante en este punto remitirnos históricamente a la aparición de la notación musical en Occidente. Surgió como ayuda nemotécnica, es decir, como ayuda para memorizar amplios repertorios musicales. En un principio solo servía de apoyo para aquella persona que ya conociera el repertorio musical, de tal manera que, para funcionar, la partitura requería del músico conocedor de ese repertorio. Poco a poco fue desarrollándose de modo que servía como recurso para darle vida nuevamente a una pieza musical sin necesidad de que el intérprete conociera de antemano dicha pieza: solo se requería que el músico conociera la tradición musical a la cual pertenecía. Las partituras permitieron entonces que la música viajara separada del compositor y separada del cuerpo del músico. La música podía ser reproducida y reinterpretada por diferentes músicos en diferentes lugares, simplemente con la difusión de la partitura. En parte, este fenómeno hizo pensar que en las partituras estaba "la música", ya que podía ser reproducida de forma masiva, pero a la vez hizo olvidar que un requisito indispensable para ello era la familiaridad del intérprete con la tradición musical a la cual respondía esa partitura.

En la tradición musical occidental, la partitura sirvió (y sirve] como un excelente soporte de ideas musicales dentro de unos lenguajes específicos y en unas tradiciones particulares. La mejor manera, entonces, de plasmar una idea musical, de dejarla registrada en un soporte físico como el papel para garantizar su permanencia en el tiempo y su transmisión y difusión era la partitura, mientras que cualquier interpretación de ella quedaba en el terreno de lo efímero y condenada al olvido. Una partitura así queda entonces a mitad de camino entre el uso descriptivo y el prescriptivo: sirve para describir una idea musical y para prescribir cómo interpretarla nuevamente.

Si bien este fue el principal uso de la partitura durante varios siglos [registrar las ideas musicales y así facilitar su

5. Quizás, la única representación completa de un hecho sonoro sea la gráfica de una onda [Hopkins, 1966, p. 311]. Si bien una gráfica de este tipo resulta muy útil al poder hacer que un equipo reproduzca nuevamente la señal musical a partir de ella, no permite ser "leída" por un músico para deducir de allí las alturas, el ritmo, la forma, las armonías, entre otros. Se trata entonces de un muy buen mapa en escala 1 a 1, pero como tal no permite ser interpretado analíticamente (por ejemplo, un músico no podría tocar la pieza que representa a partir de mirar la gráfica de la onda]. 


\title{
MAZURCA
}

\author{
op. 6 n. 4
}

dedicada a la Condesa Paolina Plater

(publicada en 1832)

Presto, ma non troppo $d=220$
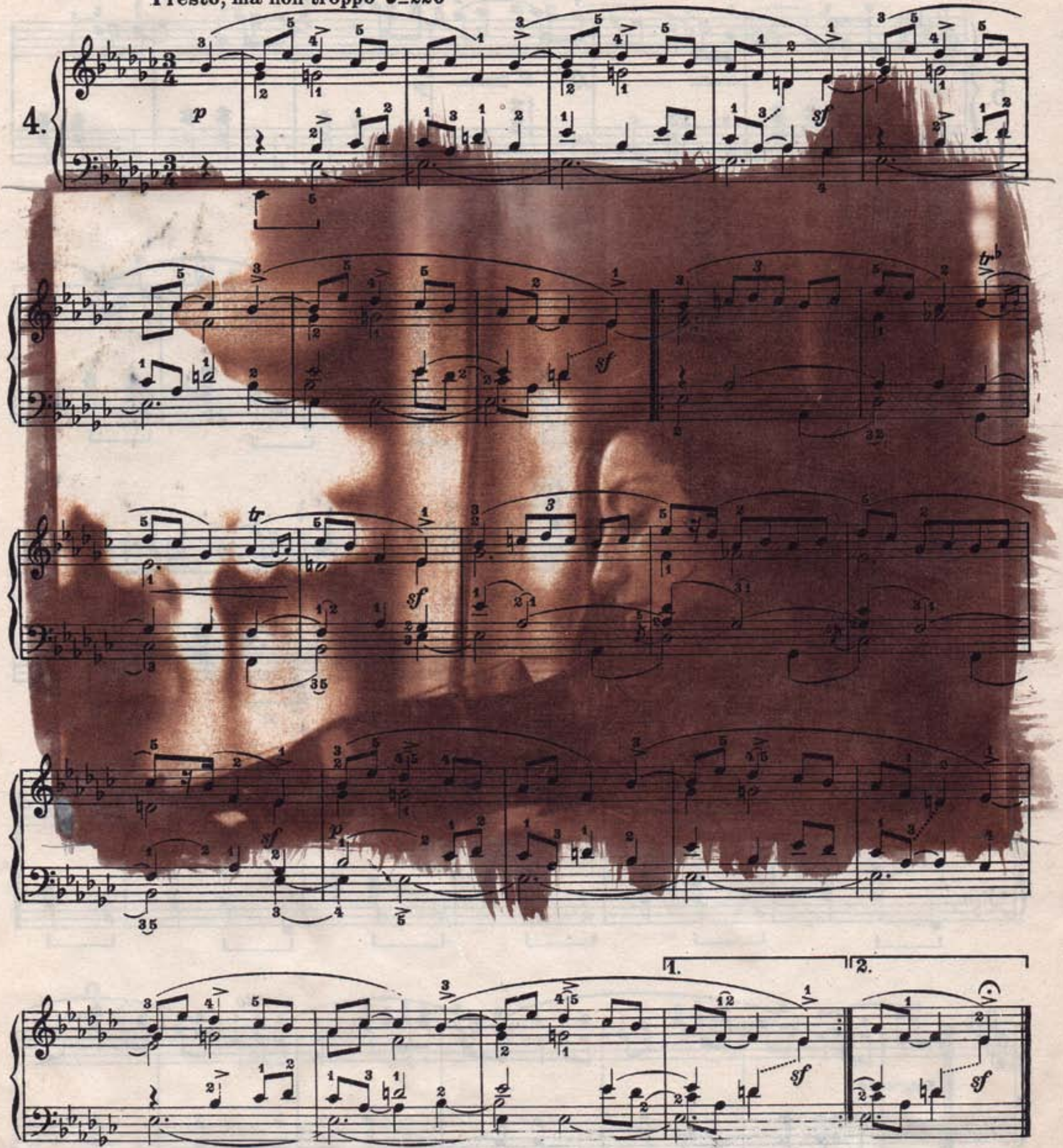
Kallitipia sobre partitura, impermeabilizada con almidón de Maíz. Gabriel Molina, 2014. Tomado de: https://www. flickr.com/photos/breatheoutnow/

recordación, reproducción y su difusión masiva separada del compositor], vale la pena preguntarnos por su estatus una vez surgen los medios eléctricos y electrónicos de grabación musical. Y más aún, con la masificación de estos medios en los últimos años debido al bajo costo que le han significado la aparición y la difusión de la tecnología digital. En una época en la cual los teléfonos graban, se consiguen grabadoras digitales multipistas a bajo costo y de fácil manejo y transporte, en que los archivos de audio viajan más rápidamente vía web que lo que cualquier partitura física puede hacer, ¿no será que la partitura convencional como soporte de grabación, como forma de registro, pierde mucho de su sentido? La partitura, entonces, sigue manteniendo su utilidad como forma de descripción de algunos parámetros de eventos musicales, sigue siendo útil para determinar cómo interpretar algunos de esos parámetros, pero pierde poder como soporte para fijar, grabar, recordar y difundir la música. Estamos en una época en la cual difundir la música ya no puede ser asociado principalmente con difundir partituras sino grabaciones sonoras puesto que las grabaciones tienen un estatuto ontológico mucho más cercano a "la música" que las partituras [es decir, las grabaciones son la música] ${ }^{6}$.

\section{Tres consecuencias pedagógicas}

Una vez entendida la partitura como una forma particular de notación de algunos parámetros musicales, podemos plantear tres consecuencias pedagógicas para la educación musical formal.

\section{a) Ampliación de la noción de notación musical (más allá de las partituras)}

Si las partituras son solo una forma particular de representación gráfica de lo musical, podemos tener más presente en la educación musical otras formas de notación. Incluso, dentro de la tradición musical en Occidente también se han usado muchas otras formas de notación. Están, por ejemplo, los lead sheet que utilizan principalmente [aunque no exclusivamente] los músicos de jazz; las tablaturas [muy usadas por los guitarristas y bajistas de rock]; diferentes tipos de escritura para los instrumentos de percusión [muy usadas en trabajos etnomusicológicos], los rollos de pianola o rollos MIDI, entre otras. Sin embargo, todas estas notaciones mencionadas son principalmente de carácter prescriptivo, es decir, están pensadas en función del intérprete, son concebidas para poder interpretar los patrones musicales allí plasmados ${ }^{7}$. Pero, si pensamos en notaciones netamente descriptivas, notaciones a partir de las cuales no sea posible interpretar una obra sino que sirvan para determinar y analizar algunos parámetros musicales, el espectro de posibilidades se amplía. Notaciones de este tipo son por ejemplo los timeline [líneas de tiempo] que determinan la forma musical; los analizadores de espectro que nos indican el comportamiento de las frecuencias de una señal; las gráficas de paneo que indican la ubicación en la imagen estéreo de los instrumentos en una mezcla; los cifrados que indican las relaciones armónicas entre los acordes de una pieza; entre otras.

En resumen, la idea de pensar la notación musical como cualquier representación gráfica [o incluso podría ser también verbal] de unos parámetros musicales nos estimula a usar la creatividad para explotar diferentes formas de notación, según lo requiera cada situación de enseñanzaaprendizaje particular.

\section{b) Énfasis de la importancia de una educación musical corporal}

En su libro sobre las prácticas sonoro-corporales en la primera infancia en Chocó, la antropóloga Ana María Arango muestra claramente la relación que hay entre el sonido y el cuerpo, la música y el movimiento, y cómo estas dos palabras, que en Occidente han tratado de pensarse separadas, están intrínsecamente unidas (Arango, 2014].

Por esto, Ana María Arango se pregunta “¿Hasta qué punto podemos seguir comprendiendo los procesos de enseñanza-aprendizaje musical desconociendo el cuerpo [...]?” [2014, p. 45]. La propuesta entonces es asignarle un papel privilegiado y de primer orden al cuerpo dentro de la educación musical, cuerpo entendido no solo como un "recipiente" de sensaciones musicales, sino como el lugar en el cual las sensaciones musicales cobran sentido, son incorporadas, y son también creadas [usando o no la mediación de un instrumento musical] ${ }^{8}$.
6. Es interesante notar que en español recordar y grabar pueden llegar a ser sinónimos. En inglés grabar es to record, y pareciera indicar recordar. En ese sentido, grabar es recordar, es dejar registro y dejar memoria, es plasmar en un medio fijo lo que está en otro [ese primer medio original puede ser fijo o no: puede ser el canto de un pájaro, un concierto, o también una pintura o un libro]. Así, la mejor manera de recordar una música, de plasmarla para la posteridad, es grabarla. La partitura, como soporte tecnológico previo, pierde frente a la grabación esta posición privilegiada que tuvo durante varios siglos.
7. La notación gráfica musical puede ser incluso unas instrucciones escritas en texto. Es el caso, por ejemplo, de la pieza Pendulum music de Steve Reich [Stamp, 2012].

8. Hace ya mucho tiempo que en la literatura académica sobre pedagogía musical se han escuchado voces que insisten en la importancia del cuerpo en el proceso de enseñanza-aprendizaje, así como la importancia de la tradición oral frente a la escrita. Nos podemos remitir, por ejemplo, al pedagogo Jacques-Dalcroze quien desde comienzos del siglo $X X$ se hacía estos cuestionamientos [Choksy, Abramson, Gillespie, Woods, \& York, 2001, pp. 42-43]. Trabajos más recientes como los de la investigadora británica Lucy Green [2001] apuntan en sentidos similares. 
La educación musical formal en Occidente ha visto la relación del cuerpo con la música, principalmente con fines instrumentales, como máquina reproductora. El cuerpo visto como máquina implica la idea de una separación entre lo sensible y lo motriz, de tal manera que el cuerpo debe adoctrinarse para realizar movimientos iguales y precisos para poder interpretar las notas que se requieren en un instrumento, independientemente de las sensaciones y emociones asociadas. Esta concepción del cuerpo lo ha llevado a ser el blanco de las técnicas instrumentales, entendidas principalmente como adiestramientos mecánicos del cuerpo, medidos en términos racionales y objetivos: tocar escalas, arpegios, acordes, etc. ${ }^{9}$. Sin embargo, entender el cuerpo unido a lo sonoro y a lo sensible nos lleva a asignarle un lugar diferente en la educación musical, a pensarlo no exclusivamente como esa máquina que reproducirá las notas correctas en el tiempo correcto en un instrumento, sino como el lugar donde la música adquiere sentido físico y emocional, y el lugar desde el cual las ideas musicales deben surgir.

Si, como ya dijimos, la música no es la partitura, si no hay una tradición "no oral" en música, deberíamos darle prioridad al aprendizaje oral por sobre el escrito, y la educación a partir de lo sonoro debería primar sobre la educación a partir de lo escrito y lo visual. Y si -como muestra bien Ana María Arango - lo sonoro y lo corporal no pueden disociarse, la educación musical debe darle prioridad a lo sonoro-corporal, manteniendo el uso de lo escrito [en sentido amplio, no la partitura convencional] en un punto menos privilegiado. La notación escrita es entonces un medio o una herramienta en música - no es la música misma- y como tal, como herramienta, debe ser usada. Pensado así, resulta más fácil concebir una clase de música sin partituras que una clase de música sin sonidos o sin movimientos, sin lo aural o lo corporal. Se puede concebir una clase de música sin centrarse en la comprensión racional de lo que se hace (lo cual no quiere decir que no pueda darse una comprensión racional de lo que se hace, pero sí que no sea ese necesariamente el objetivo central], pero difícilmente se puede concebir una clase de música que no apele a las sensaciones sonoro-corporales, al sonido hecho movimiento. El cuerpo debe ser entonces el principal instrumento musical.

\section{c) mayor uso de las nuevas tecnologías de grabación y reproducción en el aula}

Si la música es lo que se oye y no lo que se ve, si la música es lo sonoro y no una representación visual [y parcial] de

9. Ya en otro texto había hecho una reflexión sobre el uso de la técnica en la educación musical universitaria. Parte de la discusión decía: "Las clases de instrumento se vuelcan en gran medida al desarrollo de una "buena técnica", ocupando gran parte del tiempo en el estudio de escalas, arpegios, acordes y diferentes ejercicios físicos para buscar mejorar la respuesta del intérprete en el instrumento, muchas veces sin establecer una conexión directa entre el tipo de ejercicios a realizar y el repertorio a abordar" [Ochoa, 2011, p. 60). ella, ¿por qué no centrar los procesos de enseñanza-aprendizaje musical a partir de escuchar y hacer música?

Aún hoy en día es común encontrar clases de música en las cuales, para acercar a los estudiantes a un repertorio en particular, el profesor o profesora lo primero que entrega [y a veces lo único] es una partitura. Incluso, como ha señalado Lucy Green [2001], en ocasiones los profesores [especialmente profesores de instrumento] le sugieren e incluso le prohíben al estudiante que escuche una grabación de la obra con el argumento de que "escuchar una versión de la obra les formará una imagen preconcebida de ella y les dificultará producir una versión propia" [Ochoa, 2011, p. 62). Sin embargo, en una época en la cual es fácil compartir archivos sonoros, resulta lógico restituirle ese lugar de importancia al sonido mismo. La propuesta, entonces, es trabajar más con grabaciones y menos con partituras, generar las primeras aproximaciones a un repertorio dado a partir de grabaciones, de tal manera que la primera experiencia que se tenga con esta música sea corporal y sensitiva, y no una aproximación racional y mecánica. Además, si no existe una tradición no oral en música, es importante primero generar en el estudiante esa familiaridad que se requiere con un género o repertorio nuevo a partir de lo sonoro o, siguiendo nuevamente con Ana María Arango, a partir de lo sonoro-corporal.

Diferentes investigaciones han mostrado que aprender música a partir de grabaciones, de interactuar con otros músicos, de improvisar y de hacer música en conjunto, todo esto sin la necesaria mediación de la lecto-escritura musical convencional, es algo usual en músicos populares y tradicionales en distintos contextos socioculturales. Lucy Green mostró esto para los músicos de rock en Gran Bretaña [2001], Eliécer Arenas lo planteó para los músicos tradicionales en Colombia [2009], y, en cuanto a estudios de caso en Colombia, Carlos Miñana lo documentó en el caso de las flautas caucanas [1987], Leonidas Valencia para las músicas en el Chocó [2010] y lo mismo plantean investigaciones sobre la música de gaitas [Convers \& Ochoa, 2007] y la música del Pacífico sur colombiano [Ochoa, Convers, \& Hernández, 2015]. Sin embargo, estas prácticas pedagógicas aún son poco usuales dentro de la educación musical formal, la cual se mantiene muy centrada en la partitura convencional como eje primordial de los procesos de enseñanza-aprendizaje.

\section{Conclusiones}

En el siglo XXI la educación musical formal ha mantenido una inercia de la manera como se hacía en el siglo XIX y casi todo el XX. Mientras la tecnología nos está pasando de la sociedad letrada a la sociedad multimedial, la educación musical -irónicamente, tratándose de una educación en lo sonoro- sigue en el paradigma de la ciudad letrada [Rama, 2004]. Sigue siendo una educación muy artesanal, que utiliza principalmente libros y la explicación directa por parte de los profesores. Las grabadoras, secuenciadores, y el uso de formatos cada vez más comunes para 


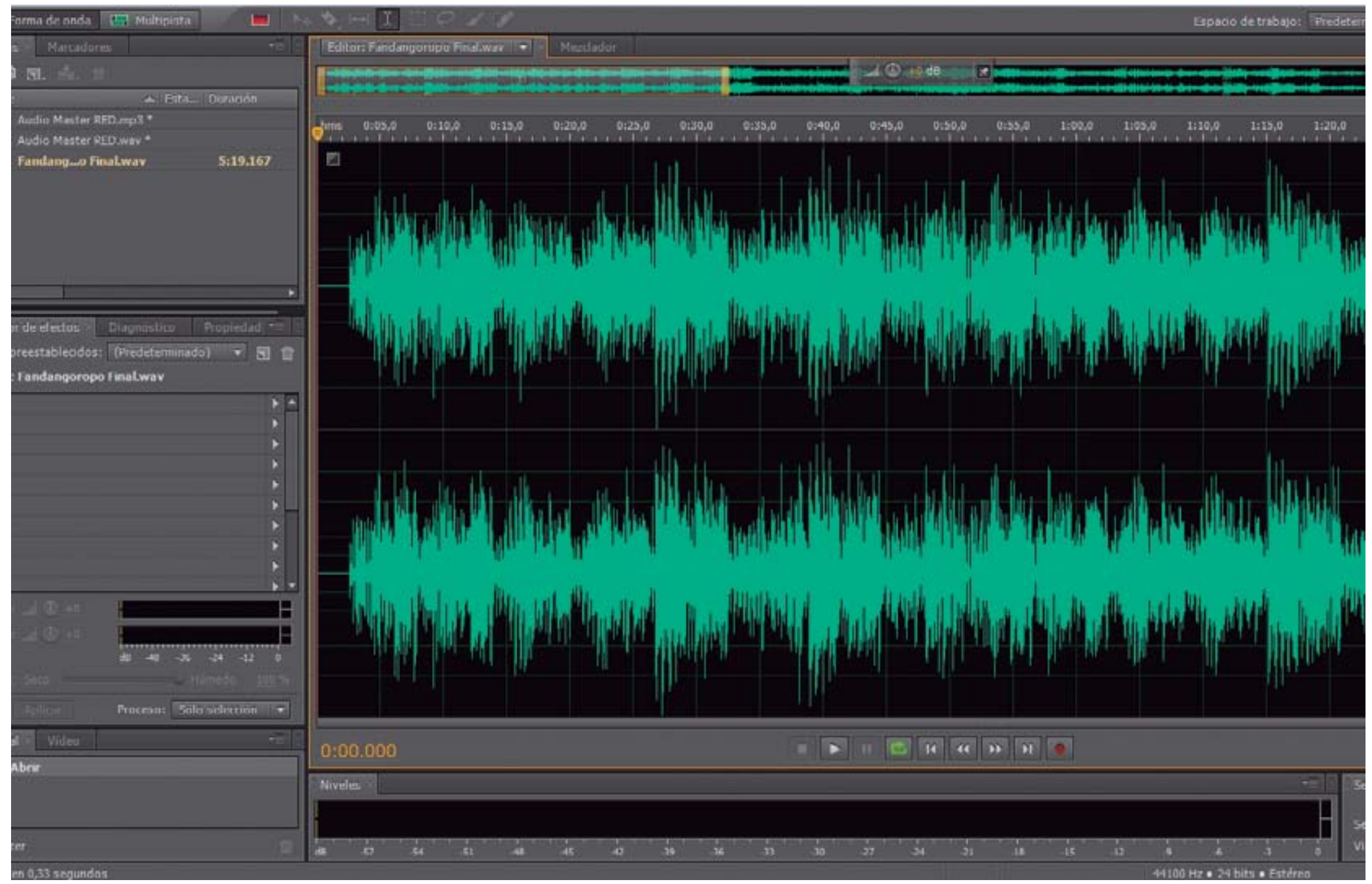

- Captura de pantalla de interfaz gráfica de Adobe Sound Boots, 2016

almacenar y compartir audios y videos no suelen ser lo suficientemente usados, como si los cambios tecnológicos de las últimas décadas no hubieran permeado las prácticas educativas. Las tecnologías pueden ayudarnos a sentir más la música, a escucharla más y verla menos, y por lo tanto pueden ayudar en la participación del cuerpo y la emoción.

Ya a comienzos del siglo XX, el pedagogo musical JacquesDalcroze se hizo las siguientes preguntas acerca de la educación musical:

¿Por qué hay tantos libros de texto sobre transposición, armonía y contrapunto, escritos en un estilo técnico?, ¿no deben primero intentar desarrollar la habilidad de escuchar los efectos que ellos describen?

¿Por qué las cualidades que caracterizan un músico real pocas veces se encuentran en una clase de música? [Choksy et al., 2001, pp. 42-43]. teniendo vigencia en buena parte de la educación musical formal hoy en día. Si bien, cuando Dalcroze se hizo esos cuestionamientos no siempre era fácil acceder a la manera de escuchar los ejemplos musicales que se abordaban en una clase de música [a principios del siglo XX la tecnología no lo facilitaba), hoy en día resulta difícil de comprender que la posibilidad de acceder a escuchar casi cualquier tipo de música en tiempo real (gracias a plataformas como YouTube, por ejemplo] no haya transformado de manera importante la educación musical formal. La partitura sigue siendo el personaje principal (notorio por ejemplo en los programas de asignatura, organizados en mayor medida a partir de libros de texto] y lo sonoro-corporal se relega a un segundo plano. Las estrategias de educación musical no mediadas por la partitura, como suele ocurrir en muchas músicas populares y tradicionales, parecen no haber permeado con fuerza los contextos educativos formales ${ }^{10}$ Una manera efectiva para salirse de esta inercia en las prácticas pedagógicas es relativizar el peso de la partitura al hacernos conscientes de su estatuto ontológico: la partitura no es la música, es tan solo una de muchas formas de notación gráfica de algunos elementos de ella,
Y otros grandes pedagogos musicales del siglo $X X$ como Carl Orff y Maurice Martenot habían planteado interrogantes similares [aunque lo habían hecho principalmente para la educación musical infantil, mientras yo extiendo la propuesta a cualquier nivel educativo]. Infortunadamente, estas preguntas siguen
10. Sin embargo, para el caso particular colombiano, las investigaciones sobre las músicas populares y tradicionales del país, especialmente las que han abordado las formas de transmisión del conocimiento, son relativamente recientes, por lo cual quizás habrá que esperar aún un tiempo para ver si logran permear de alguna manera la educación musical formal. 
es tan solo una de las formas posibles de representación de aspectos de lo musical. Y una vez relativizada, cada vez que pensemos en utilizar la partitura en una situación pedagógica concreta dentro del aula deberíamos preguntarnos primero: ¿qué tipo de notación[es] resulta[n] conveniente[s] y por qué?, ¿qué propósitos tendrían esas notaciones?, ¿quién o quiénes se pueden beneficiar de ellas?, ¿qué ventajas y desventajas presentaría el uso de notación occidental convencional en sus usos en el aula?

Una mirada crítica y contextual al uso de las múltiples formas de notación musical puede permitirnos usarlas de manera más eficiente y más creativa, y a la vez puede ayudarnos a colocar nuevamente el cuerpo en el lugar central de los procesos de enseñanza-aprendizaje musical. Esto debe llevarnos a una educación musical necesariamente menos racionalizada y más sonoro-corporal, menos vista y más escuchada, menos leída y más vivida.

\section{Referencias}

Arango, A. M. [2014]. Velo que bonito. Prácticas y saberes sonoro-coroporales de la primera infancia en la población afrochocoana. Bogotá: Ministerio de Cultura.

Arenas, E. [2009]. Elementos para el abordaje de las músicas tradicionales y populares desde las necesidades del músico práctico y sus contextos. A Contratiempo [www. revistaacontratiempo.com] [13].

Bent, lan D. et al. [2014]. Grove music online. Oxford music online. Oxford: Oxford University Press. Recuperado de http:/ / www.oxfordmusiconline.com/subscriber/article/ grove/music/20114 Último acceso: 28 de enero de 2015.

Borges, J. L. [1998 [1960]]. El hacedor. Barcelona: Alianza Editorial.

Choksy et al. [2001]. Teaching music in the twenty-first century. New Jersey: Prentice-all.

Convers, L., \& Ochoa, J. S. [2007]. Gaiteros y tamboleros: material para abordar el estudio de la música de gaitas de San Jacinto, Bolívar, Colombia. Bogotá: Editorial Javeriana.

Ellingson, T. [1979]. Don rta dbyangs gsum: Tibetan chant and melodic categories. Asian music, 10[2], 112-156.

Green, L. [2001]. How popular musicians learn: a way ahead for music education. Inglaterra: Ashgate Publishing Limited.

Hopkins, P. [1966]. The purposes of transcription. Ethnomusicology, 10[3], 310-317.

Miñana, C. [1987]. Músicas y métodos pedagógicos, algunas tesis y su génesis. A Contratiempo: música y danza, 78-83.
Muñoz, C. [2009]. To colombianize Colombia: cultural politics, modernization and nationalism in Colombia, 1930-1946.

O'Brien, M. [2010]. Disciplining the popular: New Institutions for Argentine Music Education as Cultural Systems. [Tesis para optar al título de doctorado en Musicología]. Austin, Texas.

Ochoa, J. S. [2011]. La 'práctica común' como la menos común de las prácticas: una mirada crítica a los supuestos que configuran la educación musical universitaria en Colombia. [Tesis de Maestría en Estudios Culturales]. Bogotá: Pontificia Universidad Javeriana.

\section{8}

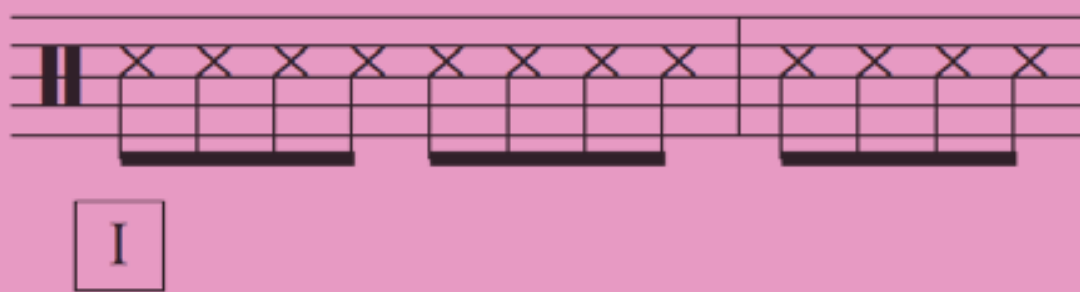

\section{Mambo}

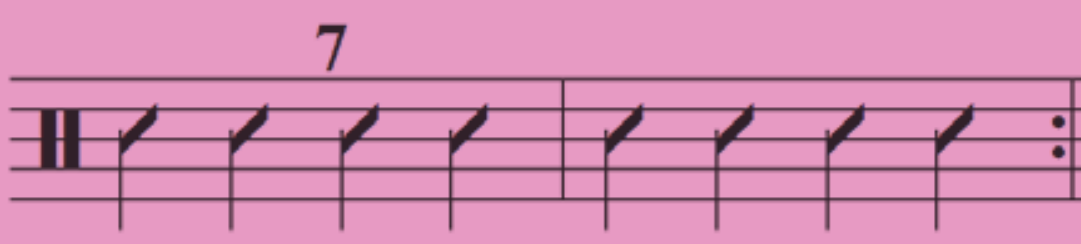

\section{K $\quad$ Mambo 2}

298.

16

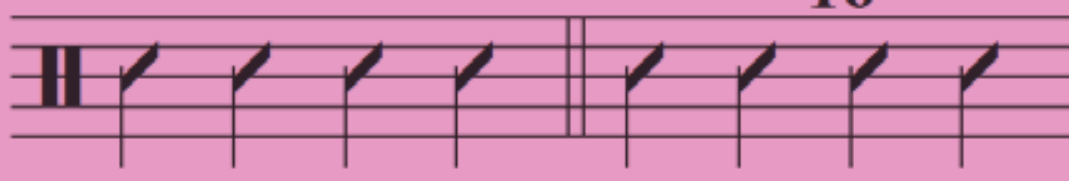

N Coda

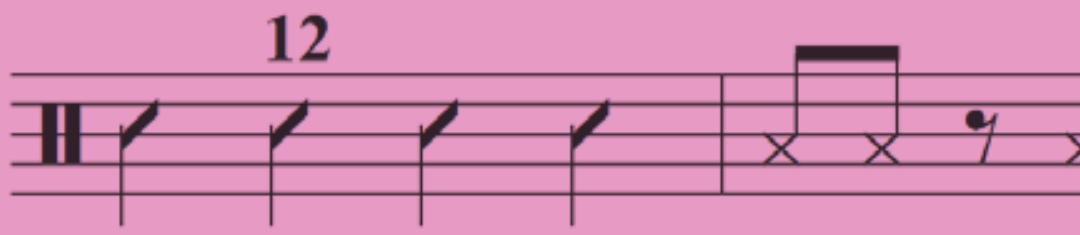




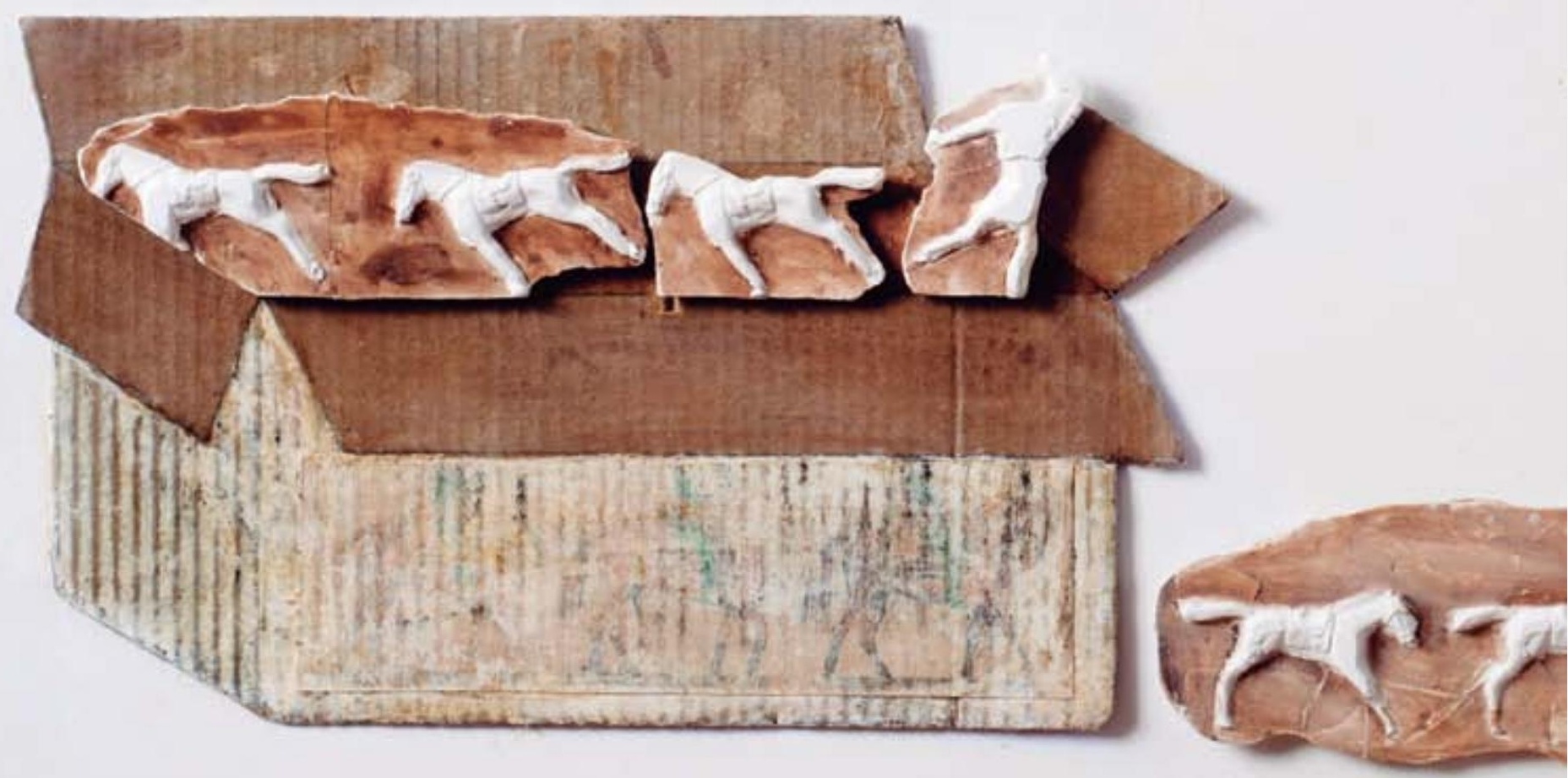




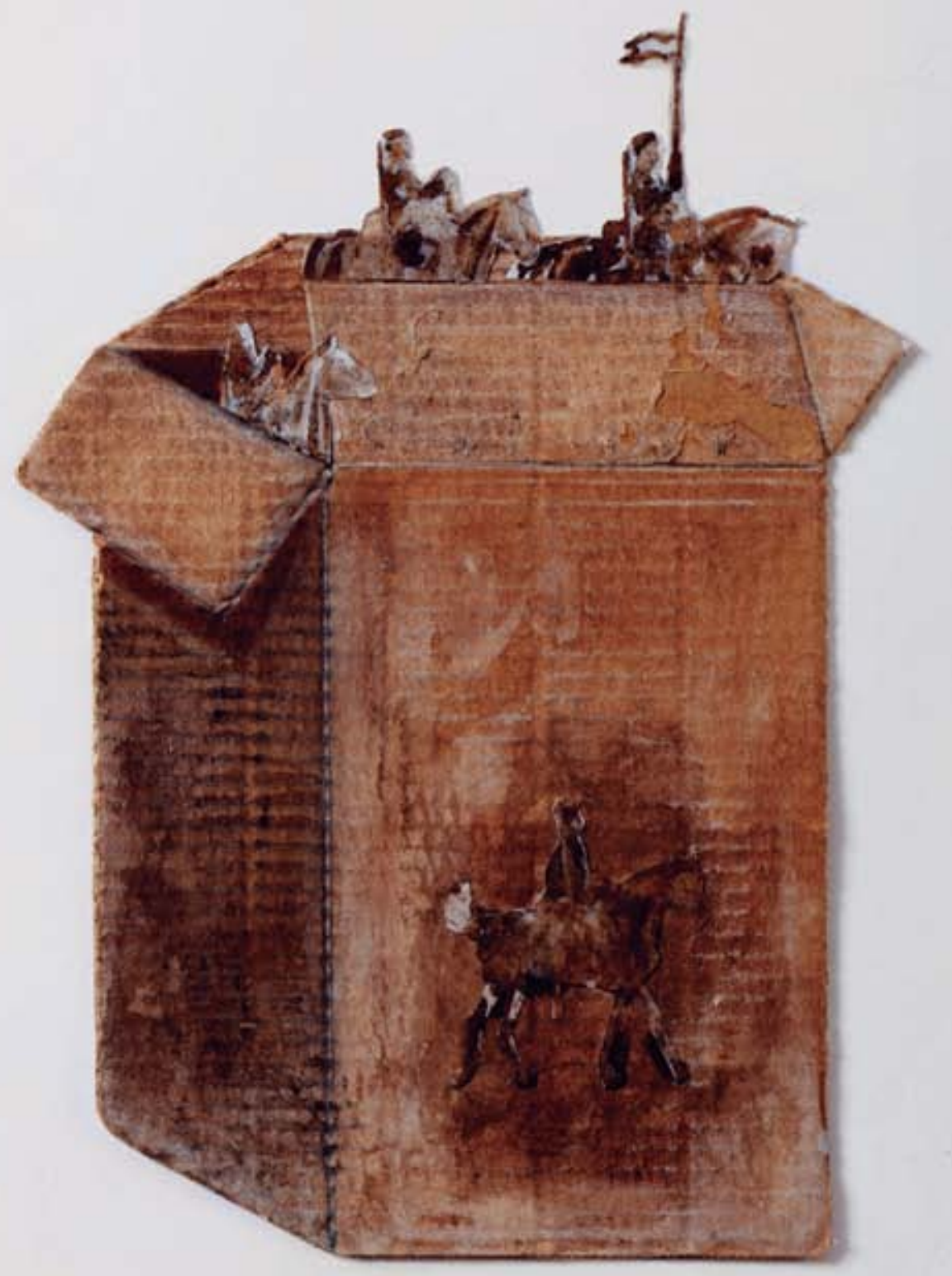

